\title{
Energy evaluation of production in agro-industrial complex
}

\author{
Andreev Leonid \\ Mechanics and technology Institute \\ Federal state budgetary educational institution of higher \\ education "State agrarian University of Northern Zauralye" \\ Tyumen, Russia
}

\author{
Yurkin Vladimir \\ Mechanics and technology Institute \\ Federal state budgetary educational institution of higher \\ education "State agrarian University of Northern Zauralye" \\ Tyumen, Russia
}

\begin{abstract}
The main task of an agricultural enterprise is the production of a certain quantity of products. Any production activity is associated with energy spending. And before any production there is a question - what amount of energy will be required at the existing level of technology for obtaining this product, and in general, is there any point in spending that amount of energy? Perhaps it is more expedient to use the means invested in energy resources to purchase finished products? Therefore, there is always a problem in determining the economically expedient relationship between the energy expended on the production of a certain product and the amount of output produced.
\end{abstract}

Keywords-economic efficiency, energy intensity, energy resources, energy evaluation.

\section{INTRODUCTION}

In a broad sense, the solution of the problem of determining the economically expedient relationship between the energy spent for the production of a certain product and the quantity of products produced allows one to answer the following questions:

- determine the required amount of energy to produce a given number of products;

- evaluate the efficiency of production (enterprise, technology) by the ratio: "energy is spent - products received";

- solve the inverse problem: to estimate the possible production of a certain quantity of products for possible energy resources.

Production itself is considered in this case as a black box, in which the invested energy is invested in the form:

- machines, mechanisms, fertilizers, seeds, herbicides, etc.;

- energy resources (electricity, coal, gas, fuel, firewood, etc.);

- cost of human labor;

- Energy of nature (sun, wind, precipitation, etc.).

From the black boxб agricultural products are made in the form of grain, meat, milk, etc.
The first task is to obtain the objective function that connects the incoming energy flow $\left(\mathrm{W}_{\text {input }}\right)$ into the black box and the output stream ( $\mathrm{W}_{\text {output }}$ ) from the black box as a mathematical expression.

The second task. Investigation of the ratio $\mathrm{W}_{\text {output }} / \mathrm{W}_{\text {input }}$. Obviously, without additional feed, this ratio will always be less than 1, since there are always losses in the process. Externally, one must strive for the variant $\mathrm{W}_{\text {output }} / \mathrm{W}_{\text {input }} \rightarrow$ max. This option is possible when $\mathrm{W} \rightarrow 0$. The minimum input energy is observed, for example, in manual labor. But, in general, this option is limited by productivity. The second limiting option - growing vegetables in a closed ground in permafrost conditions. $\mathrm{W}_{\text {output }} / \mathrm{W}_{\text {input }} \rightarrow 0$, because $\mathrm{W}_{\text {input }} \rightarrow$ max. This option is limited to the cost of production. Therefore, in this problem, it is necessary, on the basis of the investigation of the ratio $\mathrm{W}_{\text {output }} / \mathrm{W}_{\text {input }}$ under constraints (at least), the possibility of producing a given quantity of production (not less than) on the one hand and the marginal cost values, on the other hand, to find economically the most preferable segments in the function being investigated.

The third task. When gathering from several possible sources of energy, it is always preferable to choose a ratio (both in their set and in a quantitative fraction), which ensures the lowest total energy expenditure for the production of a given quantity of production.

The generally accepted analysis of the economic efficiency of production activities, based on a comparison of the costs of the production process on the one hand and the finished product, on the other hand, have a number of shortcomings. First of all, this is due to price fluctuations and inflationary processes. For example, the monetary expression of costs during the sowing company period may already have a different meaning in the fall during the harvesting period and, finally, the third value in the period of sale of the finished product. In this connection, it is useful to use the energy estimation of production to study energy saving and energy consumption of agricultural production. However prices fluctuate, no matter what rates of inflation develop, the energy criterion remains unchanged and not changed by subjective factors $[1,2]$.

The use of energy indicators in the evaluation of agricultural activities is caused by a number of features of this production compared with industrial production. 
Firstly, the functioning of agricultural production requires participation not only in electromechanical, but also most importantly specific means of production - land, plants and animals. The biological component of agricultural production attests to the existence of a special bioenergetic production system aimed at achieving maximum results (appropriate crop yields in plants production and productivity of livestock and poultry in animal production). This system acts on the one hand as an energy consumer (in the form of direct and indirect energy costs), on the other hand, as a producer of new energy carriers in the form of food and by-products suitable for use as fuel (biogas based on organic wastes from field crop and livestock production ), organic fertilizer, etc. [1].

Secondly, the effectiveness of the bioenergetic system largely depends on its bioenergetic potential, which during the entire period of human farming is continuously increasing due to selection work in plant growing and animal husbandry.

Thirdly, agricultural production depends on natural factors (air temperature, precipitation, natural soil fertility, etc.); as well as from the flow of solar energy and the efficiency of its use.

Fourthly, the costs of various types of artificial energy, including human energy, are to a certain extent acting as a catalyst that increases the efficiency of the natural efficiency: photosynthesis of the biological system "earth-plant" or physiological processes in the animal body. More K.E. Timiryazev clearly formulated the task for the agricultural workers: "The cultural plant and the demands made on it are the fundamental scientific task of agriculture. Everything else is important only as much as it has to do with it".

Fifthly, for the effective functioning of the biological system of agricultural production, it is necessary to spend part of the energy to ensure the biological protection of this system, namely protection from pests, infections, weeds in crop production (pesticides, chemicals, etc.) and from infections and diseases of different genus in livestock (vaccines, antibiotics, etc.).

Sixthly, the specific conditions for farming are territorial dispersal, pronounced seasonality of production, the predominant part of non-stationary technological processes, etc. All this requires the creation of a reserve of energy and other production capacities to ensure their maximum demand during a busy period, hence the objective need for higher energy-labor ratio in agriculture compared with industry [1].

Seventhly, the peculiarity of energy consumption in agriculture is that at present about 55 branches of the national economy participate in the production of food: $82 \%$ of fixed assets and $70 \%$ of material costs are of industrial origin. This suggests that most of the energy resources are consumed outside the branch and only then through the channels of energy-economic ties goes to agriculture $[1,2]$.

An analysis of the energy efficiency of production makes it possible to determine ways of improving technological processes and complex economic systems more objectively than existing economic methods [5].
The goal of any production process is to obtain finished products. Energy at the same time has an effect on the components of the production process, participating in the transformation of the raw material into finished products.

Let's consider theoretical approaches to the solution of this problem with the example of the energy system, which represents a combination of technical elements that can form energy flows that culminate in technological processes in plant growing and animal husbandry.

\section{ENERGY EVALUATION OF PLANT GROWING}

The technological process of crop production in general can consume energy from non-renewable sources [1]. This is gas, coal, furnace and motor fuel, etc. (the general scheme of energy flows is shown in picture 1). It is always possible to find some function (in this case $f_{i}^{(1)}$ ) by which the energy resources of various non-renewable sources can be brought, on the one hand, to one unit of measurement, and on the other hand, to determine the share of the "useful" energy involved in the production process for obtaining finished products. The required amount of energy of non-renewable energy sources will be denoted by $\mathrm{Q}_{\mathrm{P} 1}$.

In general, the technological process can consume energy from renewable sources of energy (sun, wind, ground heat, etc.), in the form of electrical, thermal and mechanical energy $[6,7,8]$.

The total amount of energy consumed from renewable sources can be expressed as $\mathrm{Q}_{\mathrm{P} 2}$.

The next flow of energy that must be taken into account is energy hidden in agricultural machines and equipment, various structures, and so on. The energy of this kind $\mathrm{Q}_{\mathrm{P} 3}$ can be transferred to the final product during many production cycles.

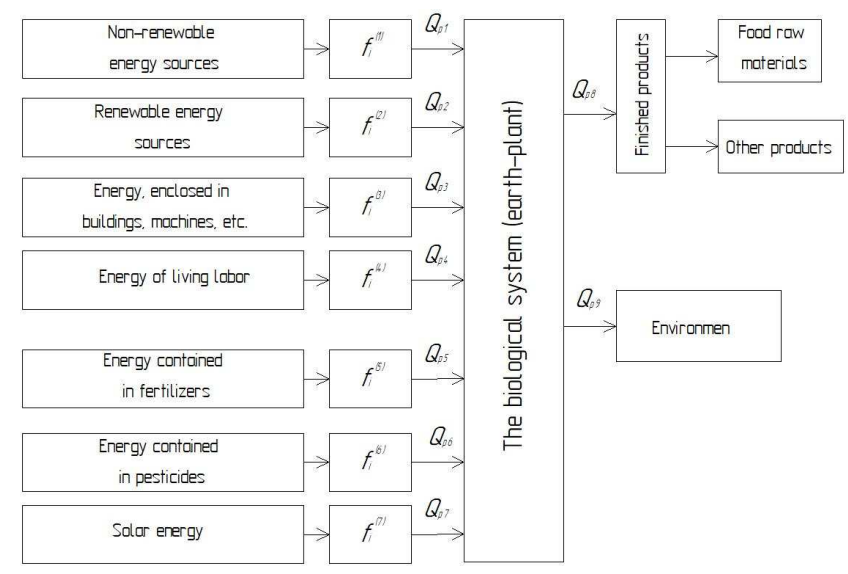

Fig. 1. General scheme of energy flows in the technological cycle of plant growing

Aside from these energy flows, it is necessary to take into account energy flows that are transferred to finished products completely during each technological cycle: energy of living labor $\mathrm{Q}_{\mathrm{P} 4}$, energy contained in fertilizers $\mathrm{Q}_{\mathrm{P} 5}$, pesticides $\mathrm{Q}_{\mathrm{P} 6}$. 
In a separate flow it is necessary to allocate so-called natural energy (in contrast to the previously considered artificial forms of energy). We denote it by $\mathrm{Q}_{\mathrm{P} 7}$ and we mean by this, first of all, the stream of solar energy directed at the biological object and providing the process of photosynthesis.

In the general case, with the help of the technological process, various agricultural products, raw materials and byproducts are produced. Each product of the process in question has its own energy equivalent. For example, the energy equivalent of $1 \mathrm{~kg}$ of milk with a fat content of $3.8 \%$ is 3,07 MJ [9]. The total amount of energy received as a result of the technological process will be composed of the energy contained in the produced main product plus the energy of the by-products (manure, straw, etc.), which we denote by $\mathrm{Q}_{\mathrm{P} 8}$.

Any technological process is inevitably associated with losses to the environment. Let us denote the total loss through QP9.

Based on the general scheme of energy flows (Fig. 1), we will compose the energy balance equation and perform an energy analysis.

$$
\begin{gathered}
\mathrm{Q}_{\mathrm{P} 1}+\mathrm{Q}_{\mathrm{P} 2}+\mathrm{Q}_{\mathrm{P} 3}+\mathrm{Q}_{\mathrm{P} 4}+\mathrm{Q}_{\mathrm{P} 5}+\mathrm{Q}_{\mathrm{P} 6}+\mathrm{Q}_{\mathrm{P} 7}=\mathrm{Q}_{\mathrm{P} 8}+\mathrm{Q}_{\mathrm{P} 9} \\
\text { or } \Sigma \mathrm{Q}_{\mathrm{P} 1}+\mathrm{Q}_{\mathrm{P} 7}=\mathrm{Q}_{\mathrm{P} 8}+\mathrm{Q}_{\mathrm{P} 9}
\end{gathered}
$$

where $\Sigma \mathrm{Q}_{\mathrm{Pi}}-$ the sum of artificial energy flows.

We make a series of transformations and obtain an expression for the specific energy intensity of the produced product $\xi_{\mathrm{p}}$, i.e. ratio of the sum of artificial energy types to the energy stored in the finished product.

$$
\xi_{p}=\frac{\sum Q_{P i}}{Q_{P 8}}=1-\frac{Q_{P 7}-Q_{P 9}}{Q_{P 8}} .
$$

Let us construct the dependence $\xi_{P}=f\left(\frac{\boldsymbol{Q}_{P 7}-\boldsymbol{Q}_{P 9}}{\boldsymbol{Q}_{P 8}}\right)$ in the form of the graph in Fig. 2. The obtained dependence has a number of characteristic points. At point "A" the energy intensity of the production $\xi_{\mathrm{P}}=0$. In reality, the minimum energy intensity of crop production can be obtained by collecting "gifts" of nature - forest and ground nuts, berries, mushrooms, etc. In this case, $\mathrm{Q}_{\mathrm{P} 9} \rightarrow 0$ (it is necessary to take into account only the energy flow - the energy of living labor). In this case $\mathrm{Q}_{\mathrm{P} 8} \rightarrow \mathrm{Q}_{\mathrm{P} 7}$, and $\xi_{\mathrm{P}} \rightarrow 0$.

At point "B" the energy intensity of the product is $\xi_{\mathrm{P}}=1$. In this case, the natural energy $\mathrm{Q}_{\mathrm{P} 7}$ that ensures the growth of production due to the energy of the sun will be equal to the energy of total losses $\mathrm{Q}_{\mathrm{P} 9}$, hence the specific energy intensity of the product will be equal to $\xi_{\mathrm{P}}=1$, i.e. the amount of artificial energy is equal to the amount of energy contained in the finished product.

A significant increase in the specific energy intensity of $\xi_{\mathrm{P}}>1$ production, according to equation (2), can be observed with large losses $\mathrm{Q}_{\mathrm{P} 9}$, low efficiency in use of solar energy flow $\mathrm{Q}_{\mathrm{P} 7}$ and low bioenergy potential of the biosystem (lowyield varieties of crops or low level of agricultural technology in crop production) and as a consequence a small value $\mathrm{Q}_{\mathrm{P} 8}$.

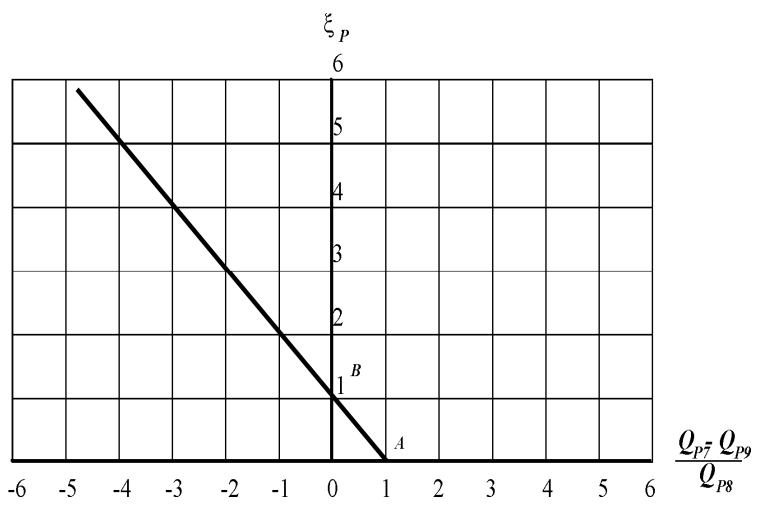

Fig. 2. Dependence of the energy intensity of crop production on the ratio: $\frac{Q_{P 7}-Q_{P 9}}{Q_{P 8}}$.

Therefore, in order to reduce the $\xi_{\mathrm{P}}$, it is necessary to reduce energy losses at all stages of production, to use biosystems with high bioenergy potential, to use advanced agrotechnics, which will make it possible to effectively use the solar energy flow.

The reciprocal of energy intensity ${ }_{\boldsymbol{\ni}_{P}}=\frac{1}{\xi_{P}}$ is called energy output or energy efficiency and is defined as the ratio of energy content of products $\mathrm{Q}_{\mathrm{P} 8}$ to total energy consumption for the production of this product, minus the solar energy flow, i.e. according to (2), we can write:

$$
\ni_{P}=\frac{Q_{P 8}}{\sum Q_{P i}}=\frac{Q_{P 8}}{Q_{P 8}-Q_{P 7}+Q_{P 9}} .
$$

Energy efficiency of $Э_{P}$ shows how much energy stored in the produced product falls on the unit of artificial energy spent. The graph of the dependence ${ }_{\boldsymbol{\ni}_{P}}=\boldsymbol{f}\left(\frac{\boldsymbol{Q}_{P 7}-\boldsymbol{Q}_{P 9}}{\boldsymbol{Q}_{P 8}}\right)$ is shown in Fig. 3.

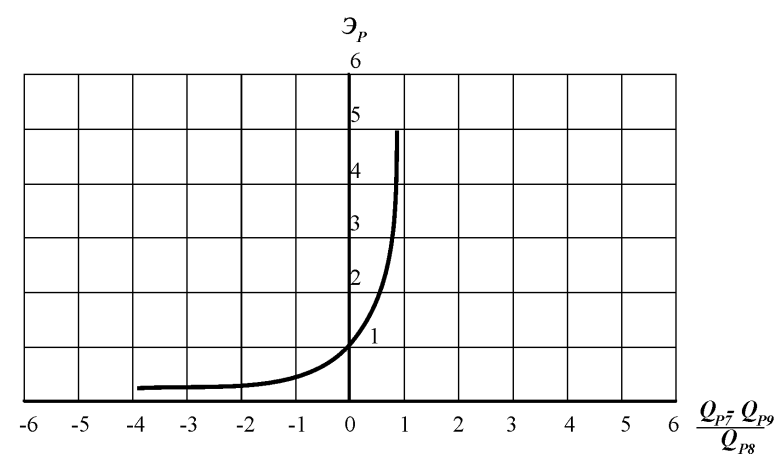

Fig. 3. Dependence of energy efficiency of crop production on ratio $\frac{Q_{P 7}-Q_{P 9}}{Q_{P 8}}$

Analysis of the graph $\boldsymbol{\ni}_{P}=\boldsymbol{f}\left(\frac{\boldsymbol{Q}_{P 7}-\boldsymbol{Q}_{P 9}}{\boldsymbol{Q}_{P 8}}\right)$ shows that energy efficiency in crop production can be significantly more than one, i.e. per unit of artificial energy expended, it is 
possible to obtain several energy units in the form of energy contained in agricultural products. This increase in energy is provided by photosynthesis, which turns the flow of the natural energy of the sun, nutrients and moisture into the biological mass.

\section{ENERGY EVALUATION OF PRODUCING LIVESTOCK PRODUCTION}

The main significant difference between the schemes of energy flows in livestock production in comparison with plant growing is the lack of direct use of the stream of natural energy of the sun. The flow of solar energy in this case is used indirectly, through the energy of the feed [10,11].

Based on the general scheme of energy flows in fig. 4 we will compose the energy balance equation for the technological cycle in animal husbandry

$$
\begin{gathered}
\mathrm{Q}_{ж 1}+\mathrm{Q}_{{ }_{2}}+\mathrm{Q}_{ж 3}+\mathrm{Q}_{ж 4}+\mathrm{Q}_{ж 5}+\mathrm{Q}_{ж 6}+\mathrm{Q}_{ж 7}=\mathrm{Q}_{ж 8}+\mathrm{Q}_{ж 9} \\
\text { or } \Sigma \mathrm{Q}_{ж 1}+\mathrm{Q}_{ж 7}=\mathrm{Q}_{ж 8}+\mathrm{Q}_{ж 9}
\end{gathered}
$$

where $\Sigma \mathrm{Q}_{\text {жi }}=\mathrm{Q}_{ж 1}+\mathrm{Q}_{\text {ж2 }}+\mathrm{Q}_{ж 3}+\mathrm{Q}_{ж 4}+\mathrm{Q}_{ж 5}+\mathrm{Q}_{ж 6}$ - is the sum of artificial energy flows.

Having carried out a number of transformations, we obtain an expression for the specific energy intensity of livestock products $\xi_{\text {. }}$.

$$
\frac{\sum \boldsymbol{Q}_{\nVdash i}}{\boldsymbol{Q}_{\text {ж }}}=1+\frac{\boldsymbol{Q}_{\nVdash 8}}{\boldsymbol{Q}_{ж 7}}
$$

Let us analyze the dependence $\xi_{ж}=f\left(\frac{\boldsymbol{Q}_{\text {ж8 }}}{\boldsymbol{Q}_{ж 7}}\right)$ shown in Fig. 5 in the form of a graph.

From the graph of Fig. 5 it can be seen that, in contrast to crop production, energy intensity in livestock breeding $\xi_{Ж} \geq 1$.

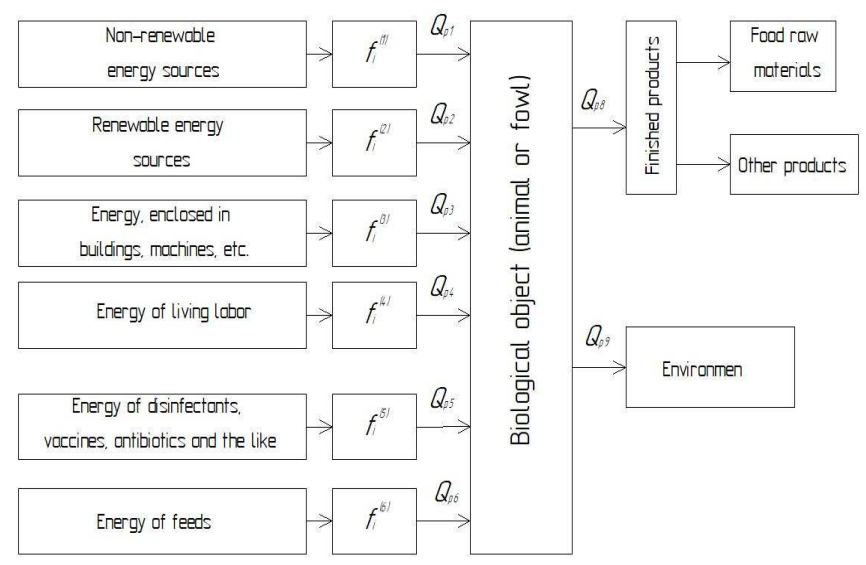

Fig. 4. General scheme of energy flows in the technological cycle of livestock production

The minimum specific energy intensity of livestock production $\xi_{\%}=1$ is possible at $\mathrm{Q}_{ж 8}=0$, i.e. There is no loss to the environment. Considering that the practical ones are always $\mathrm{Q}_{\text {ж8 }}>0$, i.e. specific energy intensity of production in animal husbandry is more than one.
The minimum specific energy intensity of livestock production can be obtained by hunting wild animals and fishing in natural water bodies.

Energy efficiency in animal husbandry $Э_{ж}$ is determined by expression:

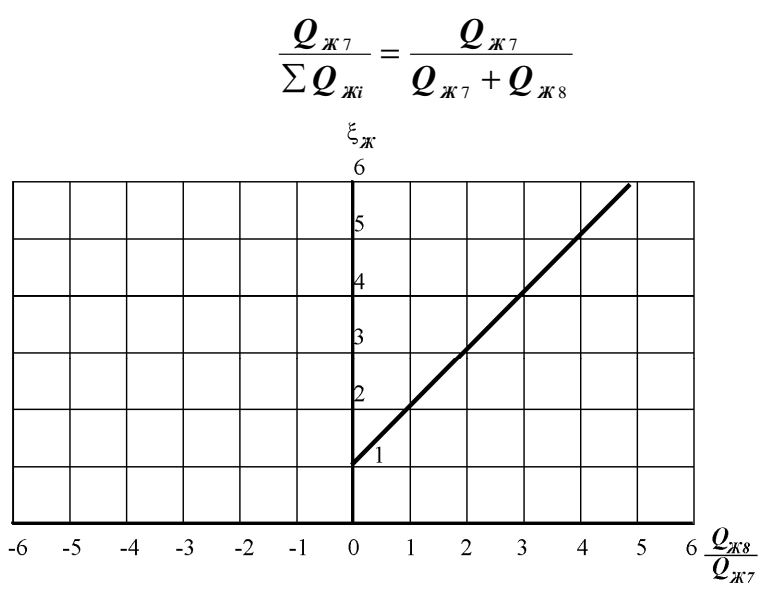

Fig. 5. Dependence of the energy intensity of livestock products on the ratio $\underline{Q_{\text {*8 }}}$ $\overline{Q_{\text {\%7 }}}$

The dependence of the energy efficiency of production in animal husbandry ${ }_{\boldsymbol{\ni}_{\boldsymbol{K}}}=f\left(\frac{\boldsymbol{Q}_{\boldsymbol{*}}}{\boldsymbol{Q}_{\text {ж8 }}}\right)$ is presented in the form of a graph in Fig. 6.

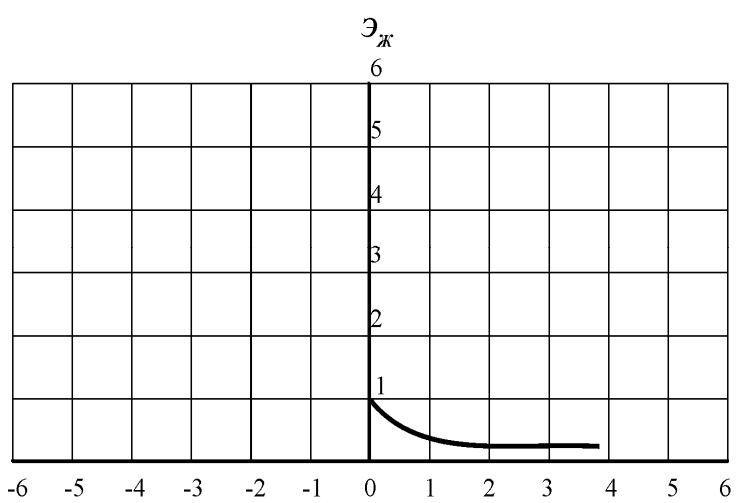

$\frac{Q_{\text {\%8 }}}{Q_{W 7}}$

Fig. 6. Dependence of the energy efficiency of production in animal $\frac{Q_{\text {\%8 }}}{\boldsymbol{Q}_{27}}$

husbandry on the ratio $\overline{Q_{\text {*7 }}}$

Analysis of the graph ${ }_{\boldsymbol{\ni}_{*}}=f\left(\frac{\boldsymbol{Q}_{\boldsymbol{*}}}{\boldsymbol{Q}_{\boldsymbol{*}}}\right)$ shows that energy efficiency in livestock cannot be more than one. The maximum energy efficiency equal to one can be obtained with $\boldsymbol{Q}_{* 8} \rightarrow 0$ or $\boldsymbol{Q}_{\text {*7 }} \rightarrow \infty$, or with simultaneous aspiration $\boldsymbol{Q}_{\text {ж8 }} \rightarrow 0$, and $\boldsymbol{Q}_{\text {K }} \rightarrow \infty$. In this case $Э_{Ж} \rightarrow 1$.

The proposed methodological approach to the energy assessment of agricultural production allows us to manage the energy consumption of this production, and therefore to choose from the technological processes the most effective 
from the point of view of the ratio of "energy expended - the energy received".

\section{METHODOLOGICAL APPROACH TO THE EVALUATION OF ECONOMICALLY FEASIBLE STRUCTURE OF ENERGY CONSUMPTION}

With the help of the dependences obtained earlier, it is possible not only to analyze the ratios $\mathrm{W}_{\text {output }} / \mathrm{W}_{\text {input }}$, but also to determine the required amount of energy (W) for a known volume of production $\left(\Pi_{\mathfrak{i}}\right)$.

$$
W=\sum_{i=1}^{n} \Pi_{i} \cdot k_{i} \cdot e_{i}
$$

where $\Pi_{i}$ - the volume of production in the general case, consisting of " $\mathrm{n}$ " of different types;

$\mathrm{k}_{\mathrm{i}}$ is the coefficient of proportionality between the amount of made product and the energy expended on its production. It is mainly determined by the adopted technology;

$e_{i}$ is the energy equivalent of the $\mathrm{i}$-th type of product.

Knowing the values of ki, ei and the planned output of different types of finished products $\Pi \mathrm{i}$, it is easy to calculate for a single technology or for a particular farm the total amount of energy required to provide this production. A possible set of different energy sources, providing the total amount of energy, can consist of a large number of different sources. At a certain fraction, the energy received from different sources is not interchangeable. For example, neither gas nor coal in a particular technology can replace electric energy. On the other hand, there are limits in which the considered sources of energy can be replaced by each other. For example, thermal energy can be obtained practically at the expense of any of the sources considered.

Therefore, one can try to determine not only the volume of the required amount of energy, but also to determine the most attractive set of sources both in kind and in number. Under the attractiveness of this or that source we will understand the availability in the given region and the economic expediciency of its use.

Theoretically, the statement of the problem reduces to the following [11]. The agricultural enterprise is a consumer of "m" energy sources $\left(A_{1}, A_{2}, \ldots A_{i}, \ldots A_{m}\right)$. In general, the quantity " $\mathrm{m}$ " includes non-renewable (electricity, coal, gas, motor fuel, etc.) and renewable sources (sun, wind, earth's warmth, etc.). The volumes of energy production by each source are set $\left(a_{1}, a_{2}, \ldots a_{i}, \ldots a_{m}\right)$. The energy consumers in the agricultural enterprise are the " $n$ " of various technological processes $\left(B_{1}, B_{2}, \ldots B_{j}, \ldots B_{n}\right)$. The volumes of consumption by each technological process are set $\left(b_{1}, b_{2}, \ldots b_{j}, \ldots b_{n}\right)$. Transport costs (expenses) are also known $\mathrm{C}_{\mathrm{ij}}$, associated with the delivery of a unit of energy from the source Ai to the point at which the technological process is realized and the energy $\mathrm{Bj}$ is consumed. At present, it is not uncommon for a case where for one reason or another, the entire need for energy can't be satisfied. In this case, it is necessary to satisfy in the first place those technological processes that, in the case of non-provision of energy, will cause maximum damage.
Therefore in the mathematical model it is necessary to take into account the amount of technological damage $r_{j}^{T}$ resulting from the dissatisfaction of the request of the technological process $B_{j}$ in energy per unit of output. Various sources of energy have different reliability of power supply, and, consequently, various specific technological damage $y_{i j}{ }^{T}$ at power supply of the $\mathrm{j}$-th consumer from the $\mathrm{i}$-th source. [7, $8,13]$.

Taking into account all of the above, the objective function will be the amount of costs for the transfer of all types of energy, the amount of technological damage caused by different levels of reliability of various sources and the amount of technological damage arising from the possible dissatisfaction of the demand for one or the other type of energy resources.

$$
Z_{1}=\sum_{i=1}^{m} \sum_{j=1}^{n} C_{i j} \cdot x_{i j}+\sum_{i=1}^{m} \sum_{j=1}^{n} x_{i j} \cdot y_{i j}^{T}+\sum_{j=1}^{n} r_{j}^{T} \cdot y_{j} \rightarrow \min
$$

Under conditions:

$$
\begin{gathered}
\sum_{i=1}^{m} x_{i j} \leq b_{i} \\
\sum_{j=1}^{n} x_{i j}=a_{i} \\
x_{i j} \geq 0, i=1,2, \ldots . m ; j=1,2, \ldots n . \\
y_{j}=b_{j}-\sum_{i=1}^{m} x_{i j}, j=1,2, \ldots n
\end{gathered}
$$

Equation (12) means that yj is the difference between the needs of $B_{j}$ and the possible supply of energy for a given technological process.

The solution of equations $8-12$ can be reduced to solving the usual transport problem of linear programming, if we introduce a fictitious point of production of energy resources $A_{m+1}$ with production volume and put $C_{m+1, j}$ equal to [11, $12,14]$.

$$
a_{m+1}=\sum_{j=1}^{n} b_{j}-\sum_{i=1}^{m} a_{i}
$$

In addition to the constraints (9) - (13), in this task, restrictions must be introduced that determine the possible share of replacement of one energy source by another on the one hand, and the share of one energy source that can't be replaced by another source on the other.

The conditions of the transport task can be conveniently set in the form of Table 1 . 
TABLE 1.CONDITIONS OF THE PROBLEM

\begin{tabular}{|c|c|c|c|c|c|c|c|}
\hline \multirow{2}{*}{$\begin{array}{c}\text { The } \\
\text { source of } \\
\text { energy } \\
\text { resources }\end{array}$} & \multicolumn{6}{|c|}{$\begin{array}{c}\text { Technological process consumer of } \\
\text { energy }\end{array}$} & \multirow{2}{*}{$\begin{array}{c}\text { The } \\
\text { volume of } \\
\text { energy } \\
\text { production }\end{array}$} \\
\hline & $\mathrm{B}_{1}$ & $\mathrm{~B}_{2}$ & $\ldots$ & $\mathrm{B}_{\mathrm{j}}$ & $\ldots$ & $\mathrm{B}_{\mathrm{n}}$ & \\
\hline $\mathrm{A}_{1}$ & $\mathrm{C}_{11}$ & $\mathrm{C}_{12}$ & $\ldots$ & $\mathrm{C}_{1 \mathrm{i}}$ & $\ldots$ & $\mathrm{C}_{1 \mathrm{n}}$ & $\mathrm{a}_{1}$ \\
\hline $\mathrm{A}_{2}$ & $\mathrm{C}_{21}$ & $\mathrm{C}_{22}$ & $\ldots$ & $\mathrm{C}_{2 \mathrm{j}}$ & $\ldots$ & $\mathrm{C}_{2 \mathrm{n}}$ & $\mathrm{a}_{2}$ \\
\hline$\ldots$ & $\ldots$ & $\ldots$ & $\ldots$ & $\ldots$ & $\ldots$ & $\ldots$ & . \\
\hline $\mathrm{A}_{\mathrm{i}}$ & $\mathrm{C}_{\mathrm{i} 1}$ & $\mathrm{C}_{\mathrm{i} 2}$ & $\ldots$ & $\mathrm{C}_{\mathrm{ij}}$ & $\ldots$ & $\mathrm{C}_{\text {in }}$ & $\mathrm{a}_{\mathrm{i}}$ \\
\hline$\ldots$ & $\ldots$ & $\ldots$ & $\ldots$ & $\ldots$ & $\ldots$ & $\ldots$ & $\ldots$ \\
\hline $\mathrm{A}_{\mathrm{m}}$ & $\mathrm{C}_{\mathrm{m} 1}$ & $\mathrm{C}_{\mathrm{m} 2}$ & $\ldots$ & $\mathrm{C}_{\mathrm{mj}}$ & $\ldots$ & $\mathrm{C}_{\mathrm{mn}}$ & $a_{n}$ \\
\hline & $\mathrm{b}_{1}$ & $\mathrm{~b}_{2}$ & $\ldots$ & $\mathrm{b}_{\mathrm{i}}$ & $\ldots$ & $\mathrm{b}_{\mathrm{n}}$ & \\
\hline & \multicolumn{6}{|c|}{ The volume of energy consumption } & \\
\hline
\end{tabular}

In this formulation, the solution of the problem is to determine the costs of obtaining and transferring energy resources to this technological process $\left(\mathrm{C}_{\mathrm{ij}}\right)$. With known quantities of this value, the solution of the problem allows us to determine the set of energy resources (by type and quantity) that provides all the technological processes in the given farm with minimal energy costs.

\section{CONCLUSIONS}

1. A methodological approach to the energy assessment of agricultural production has been developed, which makes it possible to manage the energy consumption of the given production, and, consequently, to choose the most efficient from the point of view of the ratio of "spent energy-received energy" from technological processes.

2. A mathematical model developed on the basis of the theory of linear programming is proposed, which makes it possible to obtain a rational structure of the used energy resources. This model takes into account the costs for the transfer of all types of energy, the amount of technological damage due to different levels of reliability of various sources and the amount of technological damage arising from the possible dissatisfaction of the demand for one or the other type of energy resources.

\section{References}

[1] A.V. Shpilko, V.I. Dragaytsev, N.M. Morozov, P.N. Kabanov "Economic efficiency of mechanization of agricultural production" Moscow, Russian Academy of Agricultural Sciences, 2001, 346 p.

[2] Samoylova N.V. "Methods of economic assessment of energy in agricultural production target energy industry", Izvestia Timiryazevskaya Agricultural Academy, vol. № 6. , pp. 94-101, 2013.

[3] A.G. Vozmilov, R.Yu. Ilimbetov, D.V. Astafev "The Usage of Ozone in Agriculture Technological Processes," 2nd International Conference on Industrial Engineering, Applications and Manufacturing (ICIEAM) Proseedings, 2016.

[4] S.V. Os'kin, V.A. Didych, A.G. Vozmilov, "Key Ways of Energy Saving in Pump Units for Melioration and Irrigation Systems," International Conference on Industrial Engineering, Applications and Manufacturing (ICIEAM), 2017.

[5] A.A. Andreev, A.G. Vozmilov, V.A. Kalmakov, "Simulation of lithium battery operation under severe temperature conditions," International Conference on Industrial Engineering, Procedia Engineering vol. 129, pp. $201-206,2015$.

[6] R.Yu. Ilimbetov, V.V. Popov, A.G. Vozmilov, "Comparative analysis of "NGTU - Electro" electric car movement processes modeling in
MATLAB Simulink and AVL Cruise software,'International Conference on Industrial Engineering Procedia Engineering vol. 129, pp. $879-885,2015$.

[7] A.G. Vozmilov, R.Yu. Ilimbetov, D.V. Astafev, "Theoretical and Experimental Studies of the Effectiveness of an Electrostatic Air Cleaning Filter," 2nd International Conference on Industrial Engineering, Applications and anufacturing (ICIEAM), 2016.

[8] A.S. Kizurov, I.P. lapshin, S.N. Kokoshin, "Differentiated drying of the mixtures colloidal components used in the construction of underground infrastructure," Procedia Engineering vol. 165, pp. 806-816, 2016.

[9] S.N. Kokoshin, N.N. Ustinov, B.O. Kirgincev, "The use of flexible tubular elements of the overhaul and tunnels reconstruction," Procedia engineering, vol. 165, pp. 817-828, 2016.

[10] S.N. Kokoshin, S.M. Sozonov, I.A. Shestopalov, "Theoretical justification of reducing soil adhesion to the surfaces of the excavator working body at creation underground infrastructure," Procedia engineering, vol.165, pp. 829-838, 2016.

[11] L.N. Andreev, N.I. Smolin, B.V. Zherebtsov, "Prerequisites for improving the efficiency of a wet single-zone electric filter," Philosophical and literary Journal Logos, vol. № 2. , pp. 3-4, 2013.

[12] L.N. Andreev and V.V. Yurkin, "Energy efficient technologies of microclimate creation in animal husbandry," Proceedings of the International Conference "Actual Issues of Mechanical Engineering" 2017 (AIME 2017) doi:10.2991/aime-17.2017.11

[13] F.Ya. Izakov, V.B. Fayn, "O the calculation of a system for cleaning air from dust in ventilated livestock buildings," Trudy ChIMESKh, vol. 81, pp. 130-133, 1974.

[14] A.A. Andreev, A.G. Vozmilov, V.A. Kalmakov, "Development of the Experimental Assembly for Studying the System Maintaining Battery Optimal Temperature," International Conference on Industrial Engineering, Applications and Manufacturing (ICIEAM), 2017. 